\title{
APRENDER A VER NO CANDOMBLÉ
}

\author{
Miriam C. M. Rabelo* \\ Universidade Federal da Bahia - Brasil
}

Resumo: Neste artigo discuto o aprendizado de práticas visuais no candomblé. Conforme procuro mostrar aprender a ver está diretamente relacionado ao modo como se fazem pessoas nessa religião. Uma parte importante desse processo envolve a experiência de não ver - de ter a visão repetidamente limitada por outros. Reforçada por um conjunto de práticas, contextos e modos de sociabilidade, essa experiência contribui para formar pessoas que aprendem a ver um excesso oculto sob o visivel (ou repousando ao seu lado), que aprendem a ver o invisível. Na conclusão aponto para o tipo de mundo que as práticas visuais do candomblé tanto descortinam e quanto ajudam a instaurar.

Palavras-chave: aprendizado, candomblé, percepção, práticas visuais.

\begin{abstract}
In this paper I discuss the process by which novices learn to see in the AfroBrazilian religion known as candomblé. As I try to show learning to see is intimately tied to way by which persons are constructed or "made" in candomble cult houses. An important part of this process involves the experience of not being able to see, of having one's vision repeatedly restricted by others. Reinforced by a series of practices, situations and modes of sociability, this experience helps form persons wholearn to see an excess hidden under the visible (or lying beside it), persons who learn to see the invisible. The paper concludes by identifying the world which the candomble's visual practices both unveil and help constitute.
\end{abstract}

Keywords: candomblé, learning, perception, visual practices.

\footnotetext{
* Contato: mcmrabelo@uol.com.br.
} 


\section{Introducão}

De todos os sentidos, a visão é, entre nós, aquele mais diretamente associado ao conhecimento - o verbo "ver" é frequentemente usado como sinônimo de conhecer ou saber. Como muitos já notaram, essa associação revela aspectos de nossa cultura. No Ocidente moderno conhecer tornou-se sinônimo de adquirir domínio intelectual sobre um objeto, é atividade da distância e da não participação. Ora a visão, diz-se, é justamente o sentido da apreensão distanciada e não envolvida do mundo. Daí o visualismo da cultura ocidental moderna e o consequente rebaixamento das experiências sensíveis não visuais (todas elas - tato, audição, olfato - tidas como mais participativas e, logo, mais subjetivas, do que a visão).

A crítica ao visualismo motivou uma onda de estudos etnográficos voltados a recuperar os "outros" sentidos, e descrever cuidadosamente sua significação em diversos contextos não ocidentais (Classen, 1993; Howes, 1991; Stoller, 1989, 1997). Nos seus trabalhos, passou inquestionado o pressuposto de que a visão é o sentido mais diretamente relacionado com o ideal da objetividade cultivado no Ocidente e na ciência em particular.

Mais recentemente tem havido um movimento de reabilitação da visão na antropologia. Um artigo de Ingold (2000), publicado como capítulo de seu livro The perception of the environment, marca uma virada importante nessa discussão. Aí Ingold critica fortemente a ideia de que a visão é essencialmente o sentido da análise, da distância fria e da dualidade sujeito-objeto. Sua crítica está fundada em dois argumentos. Primeiro, seguindo a trilha de Merleau-Ponty, Ingold contesta a noção de que os sentidos existem em separado, enquanto faculdades que operam isoladamente e que dão acesso a mundos fechados em si mesmos. Conforme chama atenção, experimentamos o mundo como sujeitos encarnados, com ou como corpos engajados em situações diversas. Não a visão, mas o corpo mobilizado por suas tarefas é o foco da percepção. Segundo, observa que ao perseguirmos uma descrição da experiência de ver, somos confrontados também com participação. Afinal, quando lançamos ou repousamos nosso olhar sobre qualquer coisa somos tomados por um mundo que nos solicita e que nos traga na experiência mesma pela qual o constituíamos como objeto. Assim, se a visão se reduziu a uma apreensão distanciada e não envolvida do mundo - que o transforma em objeto -, temos que interrogar não o modo da percepção visual, mas o tipo de mundo que tanto

Horizontes Antropológicos, Porto Alegre, ano 21, n. 44, p. 229-251, jul./dez. 2015 
reduziu ou empobreceu essa experiência. Trilhando esse caminho, vários autores (Grasseni, 2004, 2009; Willerslev, 2009; Zonzon, 2014) têm explorado as práticas visuais presentes em diferentes campos de atividade (que fazem parte das habilidades requeridas para o desempenho dessas atividades) e as formas e contextos em que essas práticas são ensinadas e aprendidas.

Neste artigo retomo alguns desses temas: quero tratar da visão como uma prática e explorar o modo como é aprendida em um contexto bem particular - os terreiros de candomblé. Mas ao invés de me concentrar exclusivamente na experiência de ver, pretendo inicialmente falar da experiência de não ver que integra o processo de formação dos novos adeptos e que também precisa aprendida.

Conforme procuro mostrar, a experiência recorrente de não ver, de ter a visão restringida ou bloqueada por outros no dia a dia do terreiro, gradativamente conduz os adeptos à prática de ver além do que está imediatamente dado aos olhos. Amparada em um conjunto de artefatos, formas de organização do espaço e de sociabilidade, essa prática visual é parte importante do modo pelo qual o mundo se apresenta e se faz no candomblé.

\section{Ver 0 invisível}

No candomblé o aprendizado de práticas visuais passa pela experiência da não visão e forma pessoas atentas à presença do invisível no centro mesmo do que se mostra ao olhar. Mas o que significa tomar a visão como prática? E em que sentido podemos dizer que o invisível emerge de certas práticas visuais? Antes de me ater à maneira como a visão é concebida e formada no candomblé, vou rapidamente rever algumas respostas tentativas a essa questão.

Fenomenólogos como Husserl (1985) e Merleau-Ponty $(1992,1994)$ foram conduzidos a uma reflexão sobre as relações entre o visível e o invisível por seu interesse na percepção. A reflexão de Husserl parte da seguinte pergunta: se a cada instante a consciência perceptiva tem acesso a apenas um perfil do objeto intencionado (os demais perfis sendo-lhe invisíveis naquele momento), o que nos autoriza a falar da percepção do objeto (e não de um perfil)? Percebemos o objeto, sugere Husserl, porque toda percepção envolve uma síntese (passiva) que faz com que o perfil imediatamente acessível à consciência seja dado junto a um horizonte interno e externo de outros perfis possíveis. Conforme Husserl, essa síntese tem um caráter temporal e envolve 
o movimento (tanto dos olhos quanto do corpo todo) pelo qual o sujeito explora o objeto e responde a suas solicitações.

Bastante próximo a Husserl, Merleau-Ponty (1994) destaca a centralidade do corpo, ou melhor, do sujeito-corpo engajado, na experiência perceptiva. Experiência de um corpo imerso em suas tarefas, a visão não só se prolonga e se completa na experiência dos outros sentidos, como também se prolonga e se completa na experiência linguística. Da mesma forma como não há discurso, por mais abstrato, que seja inteiramente livre de aderência ao sensível, tampouco há paisagem visual (humana) que não seja habitada por palavras (MerleauPonty, 1992). Mais do que uma síntese de dados visuais, ver é um modo de se comportar: envolve responder, via comportamento, à paisagem que se descortina ao nosso olhar. Ou ainda: envolve compreender o estilo que habita o visível através de uma atitude que é tanto um modo de se ajustar a esse estilo quanto um movimento para recriá-lo.

Alguns elementos importantes se destacam na reflexão desses filósofos, particularmente Merleau-Ponty. Primeiro o argumento de que ver é um comportamento intimamente vinculado ao modo como habitamos e estamos engajados em uma situação. Segundo, a sugestão de que ver envolve relação não só com o visível, como também com o invisível (seja este o horizonte em que os objetos se dão, seja o estilo ou idealidade que os habita).

Quando aplicada ao estudo do aprendizado da visão, a abordagem fenomenológica traz a ideia de que o aprendizado não é nem a cristalização de uma resposta a estímulos visuais nem o domínio de um código para processar esses estímulos - resulta antes de um processo de sintonização gradativa entre o corpo e seu entorno. Ingold (2010) propõe tratar esse processo como o desenvolvimento de habilidades de percepção em contextos de ação e interação e usualmente sob a orientação de praticantes.

A abordagem da percepção como prática foi radicalizada na reflexão de dois outros filósofos, muito próximos um do outro: Bruno Latour e Annemarie Mol. Apesar da distância professa com respeito à fenomenologia, ambos comungam com essa (notadamente com a fenomenologia de Merleau-Ponty) da crítica às teorias que reduzem a percepção ao processamento de estímulos sensoriais. E, como Merleau-Ponty, recolocam a percepção nos contextos práticos a partir dos quais se desenvolve.

Latour (2004) discute mais diretamente a questão da percepção em um texto que tem como tema o corpo. Conforme argumenta, corpos são 
emergentes de práticas de articulação. O exemplo de que parte Latour é o aprendizado dos odores. Narizes sensíveis a um amplo leque de odores, observa, são o resultado da articulação de diferentes agências no processo de aprendizado: professores experientes, o kit de odores usado na instrução dos novatos, livros especializados, discursos, locais e rotinas de demonstração, experimentação e teste. Quanto mais relacionado ou articulado, mais sensível é o nariz e, consequentemente, mais rico e diferenciado em odores é o mundo. Ao produzir corpos sensíveis e hábeis, práticas de articulação também contribuem para formar mundos.

Embora não esteja preocupado em travar um debate com teóricos da aprendizagem, Latour toma uma posição clara nesse campo: visto como processo de articulação, o aprendizado dos sentidos não equivale a internalização de esquemas ou códigos culturais de percepção. Nesse tipo de abordagem substitui-se a multiplicidade (os muitos mediadores que garantem a produção de um corpo sensível) pela dualidade interior/exterior (afinal é a operação do código, devidamente internalizado, que permite a percepção culturalmente adequada do ambiente exterior). Tratar o aprendizado como processo de articulação é colocar o acento nas práticas, relações e situações que fazem emergir um corpo sensível (e que ao fazê-lo podem também produzir interiores e exteriores). ${ }^{1}$

Mol, filósofa empírica, segue a intuição latouriana: o corpo, ela argumenta, é uma realidade emergente de práticas e práticas são sempre situadas, não podem ser compreendidas independentemente da situação em que se desenrolam e que ajudam a constituir e modificar (Mol, 1999, 2008). É nesses termos que Mol critica a fenomenologia, por ter descrito a percepção enquanto experiência de um corpo universal. Diferentemente, sua abordagem assume que são as ocasiões que fazem emergir os corpos. No lugar do corpo como pressuposto ou solo de toda experiência, Mol fala de corpos situados, feitos ou praticados. E de modo semelhante à Latour, observa que a performance de um corpo é sempre também a performance de um espaço: corpo e espaço ou corpo e mundo não se opõem como sujeito e objeto.

1 Vale observar que há uma nítida aproximação entre a proposta de Latour de abordar o aprendizado como processo de articulação e a de Ingold, de tratá-lo como desenvolvimento de habilidades.

Horizontes Antropológicos, Porto Alegre, ano 21, n. 44, p. 229-251, jul./dez. 2015 
Aplicada ao estudo dos sentidos, a proposta de Mol conduz a conclusões interessantes. Ao relatarem um experimento coletivo de preparar comida e comer com as mãos, um grupo de pesquisadoras (entre as quais Mol) observou que, nesse caso, a gustação teve início muito antes que o alimento fosse levado à boca; começou no processo mesmo amassá-lo e misturá-lo com os dedos (Mann et. al., 2011). Conclusão: não só não se pode reduzir o paladar aos eventos que ocorrem ao interior de um órgão específico, como também não se pode falar de uma experiência universal do paladar: cada situação é única.

Podemos certamente estender à visão as conclusões a que chegaram Latour e Mol na descrição do olfato e do paladar respectivamente. Ver depende também de articulação e mediadores diferentes podem contribuir para formar práticas visuais muito diferentes. Enquanto prática situada, a visão não começa e não se encerra necessariamente nos olhos. Pode ser preparada pelos ouvidos ou pelas mãos, por exemplo, pode começar na experiência da suspeita ou da confiança. Não é necessariamente o sentido da distância e da análise fria. E pode incluir, junto com a experiência do visível, a apreensão do que se oculta por trás do visível ou a visão mediada do invisível.

Vejamos como isso acontece no candomblé.

\section{Fazendo pessoas no candomblé}

As práticas visuais que compõem a experiência dos iniciantes no terreiro estão profundamente ligadas ao processo pelo qual se fazem pessoas no candomblé. Para compreendê-las irei me deter brevemente nesse processo de construção.

Assim antes de tratar da visão é preciso dizer algo acerca do candomblé, das categorias de pessoas que fazem parte de um terreiro e do modo como essas são feitas. Também é preciso explicitar a noção mesma de fazer ou de feitura - que muito acertadamente é considerada pelos estudiosos como porta de entrada para a ontologia relacional do candomblé.

Um terreiro é um universo social fortemente hierarquizado, liderado por uma mãe ou pai de santo, que é responsável tanto pelos seus filhos humanos quanto pelas entidades (orixás, erês, exus, caboclos, eguns) aí reunidas e assentadas. O grupo dos filhos humanos é diferenciado a partir de critérios que se cruzam e por vezes se reforçam. Um critério importante distingue os adeptos de acordo com a experiência (ou não) da possessão: de um lado temos os 
rodantes, aqueles que são tomados por suas entidades (que viram ou rodam no santo), de outro, os adeptos que não vivenciam a possessão e são confirmados equedes (se mulheres) ou ogãs (homens), assumindo funções específicas na casa. Igualmente central é o critério etário (definido por idade de iniciação), que opera mais fortemente no grupo dos rodantes e que distingue abiãs (adeptos ainda não iniciados, mas já incorporados à casa), iaôs (iniciados que ainda não completaram a obrigação de sete anos de feitura), e ebomis (adeptos que, tendo pagado a obrigação de sete anos, ingressaram no grupo dos "mais velhos”). Equedes e ogãs já “nascem” velhos.

As entidades participam ativamente da dinâmica relacional dos terreiros. Na cosmologia do candomblé, todo ser humano é filho de um orixá - que é o dono de sua cabeça. Os orixás existem em múltiplos planos - no plano geral são divindades, dotadas de personalidade e de uma história de feitos e alianças, ligadas a forças da natureza e/ou a certas atividades; no plano individual, cada pessoa está vinculada a uma versão única e insubstituível do orixá geral, comumente referida como o santo daquela pessoa (Bastide, 1973, 2001; Goldman, 1987, 2005). Além do santo, dono de sua cabeça, a pessoa está vinculada a outros orixás (e caboclos e erês) em uma composição que é gradativamente ativada no terreiro e que em alguns casos é referida como o carrego.

Embora cada ser humano, independentemente de ser ou não de candomblé, é filho de um orixá, seu ingresso em um terreiro requer que esta relação seja “feita”. Mas fazer aqui é menos um ato de criação do que uma prática de instituição - é ativar uma relação que já existe, ou criar condições para ela possa ser efetivamente cultivada e desenvolvida. É abrir caminho para uma sequência. O termo "feitura” é utilizado nos terreiros para falar do processo de iniciação pelo qual o noviço, firmando a relação com seu orixá, torna-se iaô de uma casa. Os pesquisadores, entretanto, têm empregado a palavra em um sentido mais estendido para tratar da longa trajetória pelo qual o adepto firma relação com as entidades que compõem sua cabeça. Nesse sentido estendido, fazer aponta para um longo processo de crescimento e maturação.

No candomblé a feitura do noviço é também a feitura do santo - o processo não só institui uma relação como conduz à individuação gradual dos entes que dela participam. À medida que a pessoa cumpre ou "paga” as obrigações que seguem à feitura - ritos de 3, 7, 14 e 21 anos que envolvem, entre outras coisas, dar de comer às entidades do carrego - ela se torna, a um só tempo, mais relacionada e mais individuada - se destaca justamente por seus vínculos. 
Tanto ela quanto as entidades acumulam mais atributos e arrastam consigo mais relações - e, com isso, ganham mais margem de manobra no terreiro.

A feitura não produz apenas a relação entre noviço e santo - vincula ambos ao terreiro, colocando-os sob a responsabilidade de todos que contribuíram para deslanchar a contento esse processo. $\mathrm{O}$ iaô é quase um prolongamento destes outros - sua mãe de santo, sua mãe e pai pequenos, seus mais velhos. Deve-lhes obediência e sente-se dependente deles. A cada obrigação que paga, avança na hierarquia da casa e ganha mais autonomia. Mas a autonomia conquistada não o retira do emaranhado de relações em que, desde a feitura, está envolvido; apenas o faz se destacar como um nó que pode arrastar consigo outras tantas e novas relações.

\section{0 aprendizado dos iniciantes e a visão de soslaio}

Antigamente o povo de candomblé fazia tudo escondido pra ninguém ver, não ensinava nada.

Mãe Beata.

Por isso é que tudo mundo hoje corre pros livros, porque no terreiro ninguém quer ensinar nada.

Dona Dulce, ebomi.

“Minha religião é de muito detalhe.” Com essa observação uma equede de um terreiro de Belo Horizonte recebeu a jovem pesquisadora que começava a adentrar no universo das religiões de matriz africana (Damasceno, 2014, p. 5). A observação não só fala do candomblé - do estilo que lhe é característico - como também da árdua tarefa de aprender a dominar todos os detalhes da religião, tarefa que define o cotidiano dos iniciantes no terreiro.

Iaôs precisam não só aprender a fazer de modo competente as tarefas que lhe são designadas, como também precisam aprender a aprender no modo próprio do candomblé. Como acontece com qualquer caso de aprendizado, é preciso adotar a atitude e disposição requeridas para deslanchar o domínio gradativo de um conhecimento ou habilidade - seja a sensibilidade requerida para manipular os materiais com que se trabalha, seja a atitude condizente para com aqueles que estão na posição de instruir. No caso do candomblé há 
muita elaboração em torno desse aspecto - não apenas porque as tarefas a desempenhar exigem atenção e destreza, mas porque a comunidade do terreiro precisa, além de transmitir o conhecimento, fazer pessoas e conduzir sua gradativa transformação.

Mas como iaôs aprendem no terreiro? Em primeiro lugar vale notar que o iaô novo é tratado como alguém cujo conhecimento não conta. Conta-se com ele para realizar tarefas enfadonhas do dia a dia - conta-se em poder mandar nele na expectativa de que, sendo iaô, irá obedecer. Mas é preciso, aos poucos, encaminhar seu aprendizado - instruir os novatos é responsabilidade dos mais velhos. Dois elementos tornam esse processo particularmente difícil para os iniciantes. Primeiro, como observou Goldman (2005), aprender no candomblé assemelha-se a um processo de catar folhas. Há poucas situações definidas como situações de aprendizado (e sua ocorrência depende da boa vontade daqueles que sabem). Além disso, não há um corpus de conhecimento pronto para ser transmitido aos mais novos, cabe a estes juntar, pouco a pouco, os vários pedaços a que logram ter acesso.

Aprender leva tempo. Não só porque juntar porções de conhecimento é tarefa que não se resolve segundo uma linha de continuidade previamente estabelecida, mas ao sabor de oportunidades que podem ou não se oferecer, mas também porque se exige do iaô que viva intensamente o lugar que é lhe reservado no terreiro: e esse é o lugar de alguém que está na base de uma hierarquia mais ou menos rígida. Para aprender, iniciantes devem primeiro obedecer. $\mathrm{Ou}$ melhor, obedecer é condição para que o aprendizado seja deslanchado e essa condição também precisa aprendida.

Iaôs fazem o trabalho pesado da roça. Antes da feitura, na condição de abiãs, já se acostumaram ao trabalho de lavar e engomar, ajudar na cozinha, arear panelas, tratar dos bichos sacrificados, lavar chão, tirar couro de bode, etc. O trabalho é cansativo, mas para muitos a dificuldade maior não está no trabalho. Reside na condição de subordinação que define qualquer uma de suas atividades e que é fortemente inscrita em seu corpo, no espaço em que se movem (ou se não se movem) e nas possibilidades abertas aos outros, mais velhos, de interferir em ambos (de mandar). Na verdade, ao ingressar na dinâmica cotidiana do terreiro, os iniciantes logo percebem que mais do simples obediência, espera-se deles a exibição contínua, ritualizada, de sujeição frente aos mais velhos. Muitos contam de sua dificuldade de se ajustar às fortes demandas de sujeição que marcam a vida no terreiro. Sentem seus limites 
desafiados, queixam-se de humilhações e abusos de poder, e vivem uma tensão nem sempre resolvida entre o apelo do candomblé ou o chamado do santo e seu desejo de autonomia.

As dificuldades enfrentadas pelos mais novos não param por aí: à demanda de sujeição soma-se o que muitos descrevem como a resistência dos mais velhos em passar adiante o conhecimento que acumularam e preparar os mais novos para o desempenho de tarefas no terreiro. Em algumas casas é-lhes negado o acesso à cozinha, cujo domínio é mantido fortemente nas mãos de ebomis experientes no preparo das comidas dos orixás. Em outras, ebomis zelosos e autoritários monopolizam tarefas que poderiam já distribuir entre os mais novos. E como não podem reivindicar acesso, resta aos iniciantes esperar a boa vontade de seus mais velhos.

Nos candomblés antigos, costuma-se dizer, essa resistência de compartilhar o saber era mais acentuada: então o conhecimento era mantido firmemente nas mãos dos mais velhos e “iaô sabia seu lugar”. Há certamente muita variação nos trajetos de aprendizado disponíveis aos novatos: no candomblé cada casa é um caso. Enquanto algumas casas rezam pela "cartilha antiga", outras oferecem a abiãs e iaôs mais oportunidades de participação e aprendizado. Além disso, independentemente da orientação do terreiro, adeptos contam com possibilidades alternativas para adquirir o conhecimento que lhes é negado por seus mais velhos. Ampliam suas redes de relação no mundo do candomblé, circulam por diferentes casas e, livres dos controles que operam sobre eles em seus terreiros, aprendem mais livremente. Aprendem em circuitos de conversa e fofoca e - situação impensada pelos “antigos” - aprendem na internet, nos muitos sites dedicados a manter e ensinar a "tradição dos orixás”. Esse "aprendizado" certamente produz efeitos na dinâmica interna das casas de candomblé, mas não livra iaôs nem da submissão aos mais velhos nem da experiência de margem e ignorância que lhes é reservada no terreiro.

Entender o aprendizado no candomblé requer uma discussão sobre os modos de acesso e circulação do conhecimento religioso. Parte deste é considerado secreto (fundamento) e mantido fora do alcance não só dos de fora, mas também daqueles, de dentro, que se situam na base da hierarquia religiosa. Mas, conforme já observei (Rabelo, 2014), tão importante quanto avaliar o papel do conhecimento - na manutenção da autoridade da casa, na distinção dos mais velhos, etc. - é compreender o lugar que ocupa o não conhecimento na vida do terreiro. 
Restringir acesso ao conhecimento, explicam mães e pais de santo, é uma forma de proteger quem não está ainda devidamente preparado das energias que estão sendo manipuladas pelos praticantes experientes. Mas negar conhecimento também é um modo de promover a entrega dos iaôs, de exigir que depositem total confiança na competência e discernimento dos mais velhos, em especial, suas mães ou pais de santo. É um modo de produzir uma experiência. Ou melhor, de produzir um tipo de ser.

A falta de conhecimento dos iniciantes está estreitamente relacionada ao processo pelo qual se fazem as pessoas no candomblé. O iaô novo está preso ao terreiro e ao seu orixá e tem uma margem pequena de liberdade na relação com ambos. É ainda ignorante. Mas sua ignorância não é simplesmente uma condição inicial que deve superar com perseverança e dedicação ou o resultado de uma estratégia montada pelos mais velhos para negar-lhe acesso ao saber, é definidora de um modo de ser que é feito no terreiro.

Estar à margem define, de maneira importante, o iaô. A sua falta de conhecimento será gradativamente superada sob a orientação segura dos mais velhos e experientes, com o tempo sairá da posição de margem em que se encontra inicialmente e terá até mesmo a oportunidade de exercer controle sobre o aprendizado dos mais novos. Entretanto, assim como a submissão, a ignorância não é simplesmente o ponto de partida "natural” de um processo de acúmulo de conhecimento; é uma condição existencial que precisa ser produzida no terreiro, vivida e assumida enquanto tal pelo iaô.

Constroem-se iaôs moldando-se corpos - curvando, orientando para o chão, marcando e enfeitando - produzindo-se performances que demandam e refazem sua ignorância e submissão. Na feitura, o colar (quelê) amarrado rente ao pescoço, os braceletes de palha (contraeguns) apertados nos braços para espantar os espíritos dos mortos, os guizos balançando e badalando nas canelas são apenas alguns dos elementos que, compondo uma estética, contribuem para instaurar uma condição de dependência, fragilidade e subordinação. Nesse processo desempenha papel importante a produção de uma experiência de não visão ou de visão reduzida. Vejamos.

Iaôs e abiãs são mantidos distantes dos centros de ação que definem a vida do terreiro: seu movimento é bloqueado, sua entrada em certos espaços é interditada e sua presença em outros é fortemente controlada. Suas possibilidades de visão são continuamente limitadas. Não devem olhar de frente para seus mais velhos - baixam a vista em sinal de respeito. Passam por eles com 
o corpo curvado e o olhar baixo. Quando sentam a seu lado estão sempre em um nível abaixo - acocorados ou em tamboretes. Nos ritos internos do terreiro - como o corte dos bichos - são posicionados distantes da cena principal, sentados em esteiras e privados de mobilidade, enquanto equedes e ebomis movem-se com relativa liberdade e bloqueiam sua visão - às vezes de modo bem explícito.

O mundo percebido dos iniciantes é, em grande medida, orientado para o chão: pisam descalços, mantêm o olhar baixo e é no chão que desempenham muitas de suas tarefas. Demonstrar interesse no que fazem os mais velhos erguer os olhos para ver (junto com apurar os ouvidos e, pior ainda, perguntar) - é sinal de pressa, de que se quer chegar logo à posição que os outros alcançaram com paciência e a custo de muito esforço, é prova de que se quer cortar caminho. Iaôs devem esperar pacientemente o momento em que serão chamados a ver - que é também o momento de fazer e participar. E esse momento não cabe a eles determinar.

Mas a visão do iaô não é restringida apenas pelos mais velhos - é com muita frequência "anulada” ou diminuída pela presença do orixá em seu corpo: iaôs sem a obrigação de três anos e especialmente no primeiro ano que segue à feitura estão particularmente abertos à serem tomados pelo santo, dono de sua cabeça. ${ }^{2}$ Muitas ocasiões chamam o santo e fazem-nos virar (termo comumente usado nos terreiros em referência à possessão). Tocou-se na festa para o orixá, dono de sua cabeça, o iaô sempre vira. Tocou-se para os orixás daqueles a quem está diretamente vinculado na feitura - a mãe ou pai de santo, a mãe e o pai pequenos, os irmãos de barco ${ }^{3}$ - ele vira. Se estes viram, ele também é tomado pelo seu orixá. Quando os rodantes se referem ao momento em que seus corpos são possuídos pelas divindades, frequentemente dizem: “Aí não vi mais nada.” E, entre o lamento de não terem podido apreciar a beleza da festa porque estavam virados e o orgulho de terem santo de verdade, queixam-se de que, enquanto ebomis, equedes, ogãs têm uma visão completa dos eventos, eles nada ou pouco veem.

\footnotetext{
2 À medida que tanto o filho de santo quanto seu orixá amadurecem, suas relações tornam-se mais pessoais e rotinizadas. Ebomis viram no santo com bem menos frequência que iaôs, em geral apenas durante as festas para seu(s) orixá(s) ou para o(s) orixá(s) da mãe/pai de santo, o que certamente é indicativo de sua posição elevada na hierarquia do terreiro (Goldman, 1987).

3 Barco refere-se ao grupo de iaôs que foi recolhido junto para a feitura, que vivenciou junto esse processo.
}

Horizontes Antropológicos, Porto Alegre, ano 21, n. 44, p. 229-251, jul./dez. 2015 
Se por um lado iaôs novos têm poucas possibilidades de olhar de frente e focar a vista para aprender o que fazem os mais velhos, ou para ver/apreciar os procedimentos e celebrações do terreiro, por outro estão fortemente presentes no dia a dia dos terreiros: sua presença e trabalho cotidianos são esperados e mesmo cobrados. Assim, em um certo sentido, têm muita oportunidade de ver - mas precisam fazê-lo sem serem vistos olhando, precisam olhar de soslaio ${ }^{4}$ e desviar a vista quando porventura observados. Aprendem a ver aquilo que a princípio não lhes cabe ver, de modo breve, a atenção dividida entre o objeto (que olham de relance, com pressa) e a presença possível de alguém que os veja olhando. Aprendem a ver fingindo desatenção.

Temos aqui a configuração de uma experiência visual bem particular: ao exercitar a visão de relance ou de soslaio, discreta e rápida, o iaô treina a atenção para ver o que não está diretamente acessível ao seu olhar. Aprende que há sempre algo que escapa à sua apreensão imediata (à possibilidade de sua visão). Esse “algo" é tanto um mundo que lhe toma tão completamente que a seu respeito ele nada ou quase nada pode saber quanto um mundo cuja visão plena, direta, lhe é continuamente negada ou obstruída pelos seus mais velhos - que ele é levado a ver de soslaio. Um mundo de forças e manipulações que não consegue ver (ou que vê apenas parcialmente), mas que lhe é sugerido pelas práticas mesmas que o tornam não visível para ele. Em outras palavras: o iaô aprende a ver um excesso não acessível nas coisas por meio da experiência de não visão que lhe é destinada no terreiro.

\section{Conduzindo o aprendizado da visão}

Uma série de práticas encaminha e reforça o aprendizado da visão que, conforme vimos, em sua fase inicial é fortemente marcado pela experiência de não poder ver. Aqui pretendo destacar três: 1) a construção de objetos e pessoas em camadas; 2) a produção de eventos ocultos dentro de outros eventos; e 3) a distribuição e multiplicação das agências.

4 Zonzon (2014) apresenta uma instigante discussão acerca da importância do olhar de soslaio na capoeira.

Horizontes Antropológicos, Porto Alegre, ano 21, n. 44, p. 229-251, jul./dez. 2015 


\section{A construção de lugares, pessoas e objetos em camadas}

Todo terreiro de candomblé conta com um amplo salão onde se realizam as festas públicas e boa parte dos ritos fechados também. Seja ele um aposento da casa onde habita a mãe ou pai de santo ou uma construção à parte é sempre chamado de barracão. No barracão de um terreiro tem uma pequena área central usualmente demarcada com lajotas de cor ou tipo diferente das que cobrem o resto do chão. Essa área central liga-se à cumeeira no teto (em algumas casas através de um poste central) - efetuando-se assim, no terreiro mesmo, a conexão entre o Aiyê (este mundo) e o Orum (outro mundo). É a ela que os filhos recém-chegados ao terreiro se dirigem, depois de terem tomado banho e vestido os trajes brancos do candomblé - se são iaôs batem a cabeça no chão, deitados; se equedes e ebomis, tocam os dedos da mão direita no chão, levando-os em seguida à cabeça. Sempre que se toca para um novo orixá durante a festa, esse gesto é refeito.

A vista desse pedaço de chão que se destaca do resto seja pelo piso diferente com que é recoberto, seja pelas práticas realizadas em torno dele, conduz o olhar não só para cima (a cumeeira), como também para baixo. Sugere uma camada não vista, subterrânea, onde forças estão concentradas. O iniciante não demora a aprender que o chão come e que por ocasião da abertura de um novo terreiro esse ponto central do barracão é cuidadosamente preparado. Aí é aberto um buraco de terra para receber oferendas que incluem bichos sacrificados, comidas secas e um certo conjunto de objetos (entre os quais, moedas e recortes de jornais contendo notícias boas). Depositados no local durante um rito especial e depois recobertos, esses materiais são os axés ou fundamentos da casa.

O chão que é demarcado com lajotas diferentes e onde foram enterrados os axés da casa é exemplo de um dos procedimentos de ocultamento mais característicos do candomblé: a composição envolvendo camadas. Os assentamentos dos orixás são também composições desse tipo (Sansi-Roca, 2006).

Por ocasião da feitura (iniciação) de um novo adepto, o orixá que é dono de sua cabeça (versão única e insubstituível do orixá geral) é assentado (ou fixado) em uma pedra (chamada de otá). Conforme salientam os adeptos do candomblé, o otá não é a representação do orixá, mas o santo mesmo, em uma de suas formas. O otá é guardado dentro de uma vasilha (ibá), que usualmente é colocada no centro de um alguidar rodeado por pratos usados para oferendas, e o conjunto, disposto sobre uma jarra comprida (quartinhão), mantido 
em aposentos de acesso restrito (os quartos do santo) ou em áreas externas apenas parcialmente visíveis aos visitantes de fora. Organizados em montagens verticais, sopeiras, vasos e pratos formam um corpo exterior visível ao mesmo tempo em que sinalizam um interior não visível, onde certos conteúdos foram depositados e descansam. Quando o assentamento vai ser lavado ou quando o santo vai comer (receber oferenda que inclui sangue de bicho sacrificado), durante ritos em que participam apenas os adeptos da casa, o conjunto é temporariamente desmontado.

A arrumação dos materiais usados nas oferendas segue um modo de composição similar. As partes dos bichos sacrificados destinadas aos orixás são depositadas em um alguidar e parcialmente recobertas seja com uma espessa camada de penas, seja com materiais como milho branco, arroz, ou feijão, também ofertados. Em alguns casos flores são “plantadas” sobre a base de grãos cozidos.

Enquanto práticas regulares de um terreiro, a composição em camadas de lugares (o centro do barracão), de pessoas (o santo assentado) e de objetos (as oferendas) orienta a trajetória da visão: das superfícies visíveis (enfeitadas, arrumadas, destacadas) para o interior não visível. Treina a atenção tanto para apreciar o que se mostra quanto para aí encontrar os sinais do que está oculto. Ensina a ver a presença latente de um conteúdo não visto.

\section{A producão de eventos ocultos dentro de outros eventos}

No dia 2 de novembro, dia de finados, muitos terreiros de Salvador fazem uma festa para Babá Egun, destinada a honrar os mortos, os espíritos dos ancestrais. Há diferenças marcantes entre as festas de orixá e a festa de Babá: estas últimas são mais fechadas, destinadas aos de dentro e a alguns poucos convidados destes, enquanto as festas de orixá são abertas a qualquer um. $\mathrm{Na}$ festa de Babá o lugar da audiência é abolido: todos devem dançar, mesmo os tocadores em algum momento, sob pena de se tornarem vítima dos espíritos dos mortos - os eguns. O movimento é imperativo, assim como a proteção que é conferida pelas faixas de pano (ojás) enroladas na cabeça e no pescoço das mulheres (cujo risco é sempre maior que o dos homens), pelos fios de palha (mariô) amarrados nos braços e pelos pontos de efum ${ }^{5}$ pintados na face.

5 Giz dissolvido em água, usado também na pintura dos iaôs durante a feitura.

Horizontes Antropológicos, Porto Alegre, ano 21, n. 44, p. 229-251, jul./dez. 2015 
Com as luzes apagadas, o barracão é iluminado à vela e os presentes, todos de branco, dançam em volta de uma grande toalha branca onde estão dispostas várias comidas apreciadas pelos eguns.

Na casa de Mãe Beata a festa em geral recebe poucos visitantes e aqueles que vêm são frequentadores da casa. Livre da preocupação de receber e fazer bonito para os de fora, a ocasião tem um clima descontraído e é, em geral, bem animada. Em 2013, excepcionalmente, o terreiro recebeu um número elevado de convidados no dia $1^{\circ}$ de novembro - algumas mulheres vieram com peças de cor e muitas não tinham trazido panos para enrolar na cabeça e pescoço. Assim houve um certo alvoroço para providenciar ojás e saias para as desavisadas (junto com uma condenação implícita daqueles que lhes convidaram). Enquanto as pessoas da casa estavam preocupadas em assegurar que ninguém entraria no barracão sem estar devidamente protegido, alguns visitantes circulavam tranquilos - havia mesmo uma senhora com uma bolsa marrom a tiracolo - ansiosos para participar de uma festa em que estariam dançando junto com o povo da casa. Observando à distância o contraste entre a despreocupação dos visitantes e o vai e vem de iaôs que, sob o comando da mãe de santo, saíam à cata de ojás para distribuir, estava uma pequena roda de filhas de santo - algumas das quais eram equedes e ebomis. "Esse povo tá assim despreocupado porque não sabe o que acontece na festa" - observou uma ebomi - "pensa que é só folia, mas festa de egum é coisa séria." "Os eguns ficam ali rondando - disse outra - tem gente que vê eles assim se aproximando." "E se tiver alguma mulher com o pescoço ou a cabeça desprotegida eles encostam mesmo." "Depois não sabem dizer o que aconteceu" - sentenciou a primeira. Enquanto se desenrola a festa - os presentes cantando e dançando animadamente à luz de vela, os eguns - invisíveis para a maioria - rondam atraídos pela música e pela comida.

Temos assim um evento composto em diferentes planos ou camadas em um plano visível dançam os humanos honrando os ancestrais; em outro, não visível para a maioria, os eguns rondam e aproximam-se perigosamente dos humanos. Entre esses dois planos circulam as Iansãs Balés da casa que se apossam do corpo de suas filhas - presenças visíveis no barracão, elas têm acesso privilegiado aos mortos a quem lhes cabe encaminhar ao Orum. Temos assim uma narrativa parcialmente oculta por outra e duas experiências que podem ou não se dar de modo associado: a animação e alegria que caracterizam a primeira ganham nova dimensão ao se mesclarem com o senso de

Horizontes Antropológicos, Porto Alegre, ano 21, n. 44, p. 229-251, jul./dez. 2015 
enfrentamento e risco vivido por aqueles que sabem estar em proximidade perigosa aos mortos.

Este modelo de evento, de narrativa e de experiência bastante comum no candomblé complementa o aprendizado da visão que para o iaô novo inclui, de modo importante, um conjunto de práticas de restrição à visão. Como essas práticas, ensina a ver um mundo não acessível ao olhar, ou melhor, ensina a ver além do que está imediatamente acessível. Como o olhar de soslaio, ensina a ver o que nossa perspectiva - localizada, temporal e humana - não nos permite ver em sua inteireza ou completude.

\section{A distribuição das agências - ou como ver é suspeitar e também reconhecer dependências}

Uma iaô de Iansã passou mal quando estava no terreiro pouco antes de ser recolhida para a feitura. A condição se prolongou - arriava-se oferenda para Iansã e nada, até que a mãe de santo decidiu ver no jogo: Oxóssi respondeu. A iaô sempre tivera um vínculo muito forte com esse orixá. A mãe de santo preparou uma oferenda para Oxóssi e logo a iaô melhorou. Oxóssi estava cobrando o reconhecimento desse vínculo. Doravante, concluiu a mãe de santo, sempre que se fizesse algo para Iansã era preciso agradar Oxóssi também.

Outra iaô passou por uma situação difícil depois de sua feitura, quando ainda estava cumprindo resguardo no terreiro. ${ }^{6}$ Seu irmão de barco já havia sido autorizado a voltar para casa, mas ela foi instada a permanecer. Nesse período o quelê de sua santa, Iansã, começou a romper; a cada dia um novo fio partia. Colar grosso de sete fios de contas amarrado rente ao pescoço do iaô em obrigação, o quelê é sinal de sua sujeição ao orixá. À primeira vista parecia que a iaô estava por trás do ocorrido, resistindo como podia à situação de subordinação em que estava colocada. Mas ela chorava inocência. A mãe de santo foi aos búzios. Era Iemanjá que, durante a feitura, já vinha disputando com Iansã a cabeça da iaô. Foi então deslanchada uma negociação com a santa: Iemanjá deixaria a iaô em paz, mas seria celebrada, com uma festa em sua honra, após o término de cada nova obrigação da iaô. No quelê da iaô, além disso, foi adicionada uma firma de Iemanjá.

6 Esse caso foi descrito por Aragão (2012). 
A mãe de santo adoeceu. Sentia-se fraca e sem ânimo, tomada de uma grande tristeza, chorava por nada. A situação deslanchou muita especulação no terreiro. Desconfiava-se de coisa feita: o terreiro estava prosperando e quem sabe outra mãe ou pai de santo, conhecidos seus, não eram responsáveis pela situação? Podiam ter sido tomados de inveja e cuidado para interromper o crescimento da casa. Falava-se a meia voz, os nomes dos prováveis culpados mal pronunciados. A mãe de santo resistia a essa explicação, não gostava de invocação. Um irmão de santo de sua confiança, agora também pai em seu próprio terreiro, veio jogar os búzios para ela. Não confirmou que a doença era coisa feita. Mas aconselhou que fosse oferecida uma cabra a Iansã, segundo orixá (juntó) da mãe de santo, que sempre lhe acudia em momentos de necessidade.

Esses três casos, ocorridos em terreiros diferentes de Salvador, revelam elementos interessantes do jogo entre ver e não ver ou entre ver o que está dado e ver o que está oculto. Em primeiro lugar temos a presença, incialmente não vista, mas apenas pressentida, de atores diversos interferindo no destino das pessoas do terreiro - Oxóssi, Iemanjá, Iansã, mas talvez também outros humanos (invejosos) - enfraquecendo (às vezes punindo) ou simplesmente cobrando reconhecimento. Assim parte da história das pessoas se desenrola em um plano não visível ou não imediatamente acessível ao olhar, que se insinua por seus efeitos - aflições, acontecimentos fora do ordinário. No terreiro esses efeitos não tardam a deslanchar todo um conjunto de práticas e técnicas de visibilização: a consulta aos búzios é uma delas bem como o preparo e oferta de comida. O jogo revela um campo de influências (tornado visível na configuração dos búzios). A oferenda confirma o jogo: afinal a comida convoca - atrai - as agências ocultas que o jogo revelou e num certo sentido já instaura sua presença (presença bem concreta de seres que comem). Mas não só: também procura interferir diretamente na disposição de agir daqueles a quem se destina (afinal a comida é um convite e, como tal, já instaura uma situação de troca). Em outras palavras, a comida torna visível tanto uma conexão já existente, mas não notada, quanto uma conexão a fazer - ou melhor, se fazendo.

Eventos desse tipo ocorrem com frequência no mundo dos candomblés. Entre os vários desdobramentos que produzem queria destacar um: agem também para treinar a visão. Deslanchando uma movimentação intensa de afetos, ensinam a ver no modo da suspeita. Treinam a atenção na busca de conexões operantes, mas não identificadas à primeira vista. Ensinam a ver o que não

Horizontes Antropológicos, Porto Alegre, ano 21, n. 44, p. 229-251, jul./dez. 2015 
está dado de modo fácil, conduzindo ao pressentimento de influências que escapam à visão ingênua.

É interessante notar que, nesse aprendizado, ver desponta também como prática ética: é reconhecer influências e dependências (ainda) não assumidas no processo mesmo de assumi-las e encaminhá-las. Envolve uma espécie de reversibilidade em que o sujeito que vê (pressente, desconfia) a atuação de possíveis outros no desenrolar de sua vida, também se vê lá, vendo, junto com esses outros - conectando-se com eles no processo mesmo de identificá-los. É bem verdade que o aprendizado da visão de suspeita frequentemente produz uma espécie de "exagero" (o termo mais usado nos terreiros é invocação) em que a pessoa vê a ação oculta de outros nos mais variados eventos de sua vida (esse é o caso das suspeitas de feitiço ou de coisa feita). Vale notar, entretanto, que essa inclinação não é mais que a forma exacerbada de uma disposição mais geral para identificar e produzir conexões. Esse modo de ver tem como contrapartida um mundo de influências que sempre pode ser ampliado pela revelação, traçado e cultivo de novas e velhas conexões.

\section{Conclusão}

Discuti como iaôs aprendem a ver no candomblé, enfocando os contextos, modos de sociabilidade e técnicas que auxiliam nesse aprendizado. Procurei mostrar que no candomblé ver envolve perceber mais do que é dado aos olhos: se estende para abarcar não apenas o visível, mas o invisível que está dentro, ao lado ou em volta dele. Conforme argumentei, o aprendizado da visão nos terreiros passa pela experiência recorrente de não ver: de ter a visão restringida ou apagada pela intervenção de outros (tanto humanos quanto orixás). E envolve em um primeiro momento a prática do olhar de soslaio - rápido, não notado pelos outros - que se abre para o que não deve e não pode ser visto. A prática do olhar de soslaio acostuma o iaô a conviver com um excesso não diretamente acessível à visão. É parte do modo pelo qual ela aprende a ver o que não está dado aos seus olhos.

Vale notar que o candomblé não é o único domínio de prática em que controles são impostos à visão, em que se aprende a ver o invisível ou a exercer a visão de soslaio. Em vários espaços marcados por divisões hierárquicas rígidas, indivíduos em posição subordinada aprendem a ver de soslaio aquilo que não é destinado à sua apreensão. Em alguns campos de prática 
especializada, por outro lado, a visão de soslaio é uma das habilidades que definem o praticante experiente e que os noviços se esforçam por dominar. Na capoeira, por exemplo, é altamente valorizada e abertamente cultivada (Zonzon, 2014), diferentemente do candomblé, em que não recebe elaboração explícita. Mas se nesses espaços também se aprende a ver o invisível através da prática da visão de soslaio, onde está a especificidade do candomblé? No código que oferece aos adeptos para interpretar os dados dessa experiência visual? Na introdução do artigo julgo ter deixado claro por que não compartilho da ideia de que a visão resulta da operação de códigos interpretativos sobre dados visuais brutos. Para responder a essa questão precisamos apenas seguir o processo de articulação que produz olhos capazes de ver o invisível no candomblé: este inclui não apenas práticas de submissão, mas também um vasto campo de práticas (incluindo-se, é claro, práticas narrativas) de povoamento da pessoa e do mundo com entidades cujo número e extensão nunca se pode conhecer totalmente.

Entre as práticas que complementam o aprendizado da visão no terreiro citei a construção em camadas de objetos, pessoas e lugares, a produção de eventos não visíveis ao lado ou dentro de outros eventos e a distribuição das agências. A primeira treina o olhar para percorrer uma trajetória que vai da apreciação das superfícies destacadas e/ou adornadas para o reconhecimento daquilo que elas ocultam ou guardam. A segunda ensina a ver com ou por meio de outros, a explorar a perspectiva para a qual abre que o seu olhar no exemplo que apresentei pessoas com capacidade extraordinária de visão e Iansã Balé forneceram uma perspectiva que abriu para a proximidade perigosa, mas usualmente não vista, dos eguns. Por fim, ao participar da busca que se instaura nos terreiros para estabelecer os agentes responsáveis pela eclosão de certas situações ou estados problemáticos, iaôs aprendem a ver a ação de outros pelos seus rastros ou efeitos, aprendem a ver conexões via o emprego de técnicas de visibilização que atuam também para forjar conexões. Aprendem a ver nos modos associados da suspeita e do comprometimento.

Neste texto tratei da visão como prática. Esse ponto de partida me permitiu explorar o aprendizado da visão no candomblé como uma trajetória que envolve a articulação do corpo por muitas entidades: os orixás, a família de santo, o espaço do terreiro, oferendas, búzios, narrativas, colares de contas, etc. Também me permitiu estender o sentido do que ordinariamente se entende por visão para abarcar os modos próprios pelos quais se vê no candomblé,

Horizontes Antropológicos, Porto Alegre, ano 21, n. 44, p. 229-251, jul./dez. 2015 
modos que incluem pressentir, suspeitar, confiar na presença, que se formam pela mediação de técnicas como o jogo e a oferenda e que conduzem não só ao visível como também ao invisível. Por fim vale notar que esse modo de ver é parte da maneira como o mundo se mostra e se faz: um mundo de excesso, de latência, de possibilidades sempre renovadas de traçar e testar conexões. Um mundo que, longe de estar assentado de uma vez por todas, está sempre em processo de se fazer: afinal cada conexão descoberta pode dar lugar a uma nova busca, pode ensejar o estabelecimento de novos compromissos. Pode dar lugar a novas vistas.

\section{Referências}

ARAGÃO, R. Ser rodante é ser-com-outros: a possessão como experiência de alteridade num candomblé de Salvador. 2012. Dissertação (Mestrado em Ciências Sociais)-Faculdade de Filosofia e Ciências Humanas, Universidade Federal da Bahia, Salvador, 2012.

BASTIDE, R. Le principe de individuation (contribuition à une philosophieafricaine): la notion de personne em Afrique Noire. Paris: Éditions du CNRS, 1973. (Colloques Internationales du Centre National de la Recherche Scientifique, 544).

BASTIDE, R. O candomblé da Bahia: rito nagô. São Paulo: Companhia das Letras, 2001.

CLASSEN, C. Worlds of sense. London: Routledge, 1993.

DAMASCENO, L. M. O navegador entre o sim e o não: um olhar sobre Exu no Ilé Asè Ala Oju Méji Ofá Otún. 2014. Monografia (Bacharelado em Ciências Sociais)-Faculdade de Filosofia e Ciências Humanas, Universidade Federal de Minas Gerais, Belo Horizonte, 2014.

GOLDMAN, M. A construção ritual da pessoa: a possessão no candomblé. In: MOURA, C. E. M. (Org.). Candomblé: desvendando identidades. São Paulo: EMW, 1987. p. 87-119. 
GOLDMAN, M. Formas do saber e modos do ser: multiplicidade e ontologia no candomblé. Religião e Sociedade, Rio de Janeiro, v. 25, n. 2, p. 102-120, 2005.

GRASSENI, C. Skilled vision: an apprenticeship in breeding aesthetics. Social Anthropology, Cambridge, v. 12, n. 1, p. 1-15, 2004.

GRASSENI, C. Good looking: learning to be a cattle breeder. In: GRASSENI, C. Skilled visions: between apprenticeship and standards. New York: Berghahn Books, 2009. p. 47-66.

HOWES, D. The varieties of sensory experience: a sourcebook in the anthropology of the senses. Toronto: Toronto University Press, 1991.

HUSSERL, E. Investigaciones lógicas 1. Madrid: Alianza, 1985.

INGOLD, T. Stop, look and listen! Vision, hearing and human movement. In: INGOLD, T. The perception of the environment: essays on livelihood, dwelling and skill. London: Routledge, 2000. p. 243-289.

INGOLD, T. Da transmissão de representações à educação da atenção. Educação, Porto Alegre, v. 33, n. 1, p. 6-25, 2010.

LATOUR, B. How to talk about the body? The normative dimension of science studies. Body and Society, London, v. 10, n. 2-3, p. 205-229, 2004.

MANN, A. et al. Mixing methods, tasting fingers: notes on an ethnographic experiment. HAU: Journal of Ethnographic Theory, Edinburgh, v. 1, n. 1, p. 221-243, 2011.

MERLEAU-PONTY, M. O visivel e o invisivel. São Paulo: Perspectiva, 1992.

MERLEAU-PONTY, M. Fenomenologia da percepção. São Paulo: Martins Fontes, 1994.

MOL, A. Ontological politics: a word and some questions. In: LAW, J.; HASSARD, J. (Ed.). Actor-network theory and after. Oxford: Blackwell, 1999. p. 74-89. 
MOL, A. "I eat an apple": on theorizing subjectivities. Subjectivity, Basingstoke, n. 22, p. 28-37, 2008.

RABELO, M. Enredos, feituras e modos de cuidado. Dimensões da vida e da convivência no candomblé. Salvador: Edufba, 2014.

SANSI-ROCA, R. The hidden life of stones: historicity, materiality and the value of candomblé objects. Journal of Material Culture, London, v. 10, n. 2, p. 139-156, July 2006.

STOLLER, P. The taste of ethnographic things: the senses in anthropology. Philadelphia: University of Pennsylvania Press, 1989.

STOLLER, P. Sensuous scholarship. Philadelphia: University of Pennsylvania Press, 1997.

WILLERSLEV, R. "To have the world at a distance": reconsidering the significance of vision for social anthropology. In: GRASSENI, C. Skilled visions: between apprenticeship and standards. New York: Berghahn Books, 2009. p. 26-46.

ZONZON, C. Nas pequenas e nas grandes rodas da capoeira e da vida: corpo, experiência e tradição. 2014. Tese (Doutorado em Ciências Sociais)Faculdade de Filosofia e Ciências Humanas, Universidade Federal da Bahia, Salvador, 2014. 